\title{
11. SISTEMA PRISIONAL BRASILEIRO EM CONTEXTO \\ DE PANDEMIA DE COVID-19: entre a expropriação de direitos sociais e as lutas dos movimentos
} sociais*

Fernanda Kilduff

\section{Introdução}

O presente capítulo objetiva debater o processo de expropriação de direitos ${ }^{1}$ no sistema prisional brasileiro, durante a pandemia de COVID-19; com ênfase na particularidade carcerária do Estado de Rio de Janeiro. Busca-se, todavia, refletir sobre as principais estratégias acionadas pelas organizações e movimentos sociais, vinculados à defesa de Direitos Humanos de pessoas privadas de liberdade.

No Brasil, em tempos de pandemia da COVID-19, a decisão de manter a política do superencarceramento, está em consonância com a estratégia negacionista de Bolsonaro, cujas declarações e comportamentos públicos, insistem em burlar a recomendação da comunidade científica internacional: enquanto não houver vacina comprovadamente eficaz; manter o distanciamento social e usar máscara, para evitar e/ou retardar a curva de contágios.

Nessa direção, a Organização Mundial da Saúde (OMS) tem orientado os Estados nacionais, a implementar medidas para a diminuição drástica da população prisional. Com isso, países como Turquia, Irã, e Portugal ${ }^{2}$, entre outros, avançaram com o desencarcera-

\footnotetext{
*DOI- 10.29388/978-65-86678-47-5-f.287-306

${ }^{1}$ Para Boschetti (2018, p.10), "a destruição, ou redução de direitos sociais no capitalismo suprimem da classe trabalhadora a possibilidade de acessar parte da riqueza socialmente produzida apropriada pelo Estado sob forma de fundo público e reduz a participação do Estado Social na reprodução da força de trabalho e suas famílias, o que impele a se submeter as for mas mais bárbaras de exploração ou permanecer no desemprego".

${ }^{2}$ Miranda, Giuliana. Por coronavírus, Portugal aprova mecanismo que pode libertar até $15 \%$ da população carcerária. Jornal Folha de São Paulo, março de 2020. Disponível em: https:// www1.folha.uol.com.br/mundo/2020/04/para-reduzir-risco-de-covid-19-parlamento-de-
} 
mento como política necessária em tempos de COVID-19, com reduções significativas do número de presos.

Todavia, no Brasil, o ex-ministro de Justiça e Segurança Pública, Sérgio Moro, declarava publicamente, em março de 2020: "a falta de dados oficiais" que justificasse tomar alguma decisão nesse sentido $^{3}$. Assim, observa-se que, até o momento da redação deste capítulo (outubro de 2020), não houve nenhuma medida significativa do Governo Federal (e tampouco dos estaduais),tendente à diminuição do contingente prisional que alcança às 776 mil pessoas. (INFOPEN, 2019).

\section{COVID-19 no sistema prisional brasileiro: velhas e novas expropriações de direitos}

O Estado brasileiro, historicamente, é um grande violador de direitos humanos. Com uma superpopulação carcerária ocupando o terceiro lugar no ranking de aprisionamento mundial, o Brasil produz e reproduz péssimas condições de detenção. Caracterizam o sistema prisional ${ }^{4}$ : espaços marcados por superlotação, estrutura precária, alimentação limitada e de péssima qualidade, acesso à água restrito, escassez de produtos de higiene e demais materiais de uso pessoal e alto índice de tortura e tratamentos cruéis, desumanos e degradantes ${ }^{5}$.

portugal-aprova-libertar-presos.shtml Acesso em: 15 de set. 2020.

${ }^{3}$ Disponível em: <https://politica.estadao.com.br/blogs/fausto-macedo/prisoes-coronaviruse-solturavirus/> Acesso em: 5 out. 2020.

${ }^{4}$ Não há homogeneidade no que se denomina "sistema prisional". Nesta pesquisa, opta-se pela seguinte definição: "conjunto de instituições que operacionalizam determinadas políticas penitenciárias". "La política penitenciaria integra la política penal, y esta última, es una respuesta a la cuestión criminal circunscrita al ámbito de ejercicio de la función punitiva del Estado." (BARATTA, 2004, p.198).

${ }^{5}$ De acordo com a Convenção Contra Tortura e Outros Tratamentos ou Penas Cruéis, Desu manos ou Degradantes (UNCAT) aprovada pelas Assembleia Geral da ONU em 1984 em seu artigo 10: 0 termo tortura designa qualquer ato pelo qual dores ou sofrimentos agudos, físicos ou mentais, são infligidos intencionalmente a uma pessoa a fim de obter, dela ou de terceira pessoa, informações ou confissões; de castiga-las por ato que ela ou uma terceira pessoa tenha cometido, ou seja, suspeita de ter cometido; de intimidar ou coagir esta pessoa ou outras pessoas; ou por qualquer motivo baseado em discriminação de qualquer natureza, quando tais dores ou sofrimentos são infligidos por um funcionário público ou outra pessoa 
A precária assistência à saúde de presos e presas pela falta de medicamentos e profissionais, a existência de doenças preexistentes como tuberculose e HIV, que hoje são responsáveis por mais de $60 \%$ das mortes ${ }^{6}$, a escassez (e sempre duvidosa qualidade) dos alimentos, a inatividade forçada, o intenso sofrimento emocional (registram-se altas taxas de suicídios nas prisões), a falta de leitos e colchões, a falta de luz elétrica e água potável em unidades de detenção superlotadas e sem adequada ventilação, entre outros determinantes, fazem com que, o coronavírus, encontre condições muito favoráveis para uma rápida proliferação.

Como destacado, uma das recomendações dos organismos de saúde para evitar a disseminação da Sars-CoV-2, versa o distanciamento social e evitar aglomerações. Acontece que a realidade do sistema penitenciário do Brasil é a superlotação, o que provoca, objetivamente, a impossibilidade de exercer o isolamento e/ou distanciamento social nas prisões.

Com relação à superlotação, cabe destacar que, o sistema prisional brasileiro conta com 436 mil vagas para 776 mil presos. Segundo a Rede de Observatórios da Segurança, a proporção de presos acima das vagas disponíveis varia em cada Estado. Os estados com maior superlotação são: Ceará, $173 \%$; Pernambuco, $172 \%$ e o Rio de Janeiro, com $70 \%$ de presos acima das vagas disponíveis ${ }^{7}$.

Segundo dados oficiais do Painel de Monitoramento do DE$\mathrm{PEN}^{8}$, até o dia 11 de outubro de 2020, havia 29.008 casos confirmados de COVID-19, 6.076 suspeitos e 109 óbitos no sistema penitenciário brasileiro (sem considerar as subnotificações).

no exercício de suas funções públicas, ou por sua instigação, ou com o seu consentimento e aquiescência (UN, 1984 apud SIMAS, 2020, p.132).

${ }^{6}$ Informação obtida no texto do projeto de lei 978/2020. Disponível em: < https://www.camara.leg.br/proposicoesWeb/prop_mostrarintegra?codteor=1870313>. Acesso em: 19 set. de 2020.

${ }^{7}$ Mello, Kátia. O sistema prisional brasileiro no contexto da pandemia de COVID-19. Portal Conexão UFRJ, 31 de março de 2020. Disponível em: <https://ufri.br/noticia/2020/04/01/osistema-prisional-brasileiro-no-contexto-da-pandemia-de-covid-19> Acesso em: 05 set. 2020.

8“Painéis de monitoramento de casos de Covid-19" (DEPEN). Disponível em: < https://app.powerbi.com/view?r=eyJrljoiYThhMjk5YjgtZWQwYS00ODlkLTg4NDgtZTFhMTgzYmQ2MGVIIiwidCI6ImViMDkwNDIwLTQ0NGMtNDNmNy05MWYyLTRIOGRhNmJmZThIMSJ9>

Acesso em:01 out. 2020. 
O relatório: "Covid-19 no sistema prisional", elaborado pelo Mecanismo de Combate e Prevenção a Tortura (MECPT/RJ, 2020), destaca que, no sistema prisional fluminense, até o dia 21 de agosto de 2020, tinham sido aplicados apenas 1,197 testes pela Secretaria de Administração Penitenciária(SEAP/RJ) para um total de 48.620 presos. Esse número indica a testagem de apenas $2,46 \%$ da população; o que equivale a dizer que $97,5 \%$ das/os presas/os, não foram testados. Também foi constatado que, das 48 unidades prisionais do Estado do Rio de Janeiro, 25 unidades, já registraram casos de COVID-19. ${ }^{9}$

Apesar da divulgação do Departamento Nacional de Informações Penitenciárias, sobre o número de contágios e óbitos; existem muitas denúncias dos próprios presos e/ou seus familiares sobre ausência de assistência médica em casos de suspeita ou confirmação de COVID-19.

Neste sentido, como atestam os relatórios elaborados pelos organismos de direitos humanos, as unidades prisionais fluminenses, negam informações sobre as condições e tratamento de presos e fluxo de saúde durante a pandemia de COVID-19.

Apesar das restrições de informação, em observações preliminares, verificam-se o agravamento de expropriação de direitos da população prisional brasileira no decorrer da pandemia de COVID-19. Procedimentos "excepcionais" reforçam violações de direitos básicos, como proibições de visitas e comunicação com familiares e defensores públicos.

A incomunicabilidade é uma grave violação aos direitos verificada durante a pandemia. Segundo Nota Técnica ${ }^{10}$ emitida pelo MECPT/RJ (2020), o impedimento das visitas, cuja avaliação deve levar em conta padrões de saúde e epidemiológicos, não exime a $\mathrm{SEAP} / \mathrm{RJ}$, de cumprir com suas obrigações de assegurar por outros

\footnotetext{
${ }^{9}$ Informação de documentos emitidos pelo Mecanismo Estadual de Prevenção e Combate à Tortura do Rio de Janeiro (MEPCT/RJ) sobre os impactos da pandemia no sistema prisional. Disponível em: <http://mecanismori.com.br/relatorios/>Acesso em:05out. 2020.

${ }^{10}$ Disponível em: <http://mecanismori.com.br/wp-content/uploads/Nota-T\%C3\%A9cnicasobre-Comunica\%C3\%A7\%C3\%A3o-e-Cartas-durante-a-pandemia-de-COVID-MEPCTRJ.pdf> Acesso em: 15 out.2020.
} 
meios a comunicação do preso com mundo externo, seus familiares e amigos.

Desta forma, a proibição de visitas de familiares para prevenir a entrada de COVID-19 no sistema não pode resultar em medidas de isolamento, confinamento e incomunicabilidade.

O que acontece no Estado do Rio de Janeiro é a suspensão das visitas sem nenhuma medida alternativa de contato com o mundo externo, provocando a impossibilidade de comunicação das pessoas privadas de liberdade com o mundo exterior e seus familiares, caracterizando o regime de incomunicabilidade.

Além do mais, em todos os relatos e denúncias recebidos pelo MEPCT/RJ, observa-se, de forma unânime, a dificuldade de familiares com relação a informação sobre o estado de saúde de presos e presas.

Cabe observar que as medidas de incomunicabilidade, especialmente as prolongadas, constituem tratamento cruel, desumano e degradante, sendo responsáveis pela gestão de danos profundos na integridade moral, psíquica e na própria dignidade das pessoas presas.

Como exemplo disso, o MEPCT/RJ acompanhou uma grave situação de uma presa com comorbidade durante a pandemia. Seu estado de saúde foi agravado em junho de 2020, com constantes internações hospitalares, fator que fez com que a Defensoria Pública realizasse um pedido de prisão domiciliar humanitária. A decisão favorável saiu no dia em que a presa veio a óbito.

No momento da recepção da notícia do óbito foi entregue à família, trinta cartas que estavam na direção da unidade. Durante todo processo de agravamento da doença e intenso sofrimento até o seu óbito, sua filha escreveu cartas que jamais puderam ser respondidas, por falta de entrega pela unidade prisional, produzindo danos profundos a integridade de sua mãe e a da própria presa, cuja comunicação, em seus últimos dias de vida, foi negada pelo Estado.

A falta de informações objetivas numa situação pandêmica, segue sendo um fator agravante no estresse e adoecimento de familiares e internos, aliado a dificuldade de transparência do órgão de 
administração penitenciária para com as demais instituições ligadas à garantia de direitos humanos em espaços de privação de liberdade.

Embora este quadro de violações agravado na pandemia se encontre registrado, provado e denunciado pelos organismos de direitos humanos ${ }^{11}$, o governo e parte importante da sociedade civil, parecem ignorá-lo.

Contudo, existem resistências e enfrentamentos. Instituições e organizações vinculadas à defesa da vida denunciam a violação de direitos humanos e apresentam propostas tendentes ao desencarceramento.

\section{Ações das organizações de Direitos Humanos}

A Frente Estadual pelo Desencarceramento/RJ, foi criada em janeiro de 2017, a partir da iniciativa de diversas organizações de Direitos Humanos, diante dos massacres acontecidos nos presídios de Amazonas, Roraima e Rio Grande do Norte $^{12}$.As organizações de Direitos Humanos que a Frente nucleia vêm denunciando o Estado brasileiro, pelas condições desumanas às quais submete às pessoas sob sua custódia.

Como destacado, é recorrente no sistema penitenciário brasileiro: a falta de água potável, camas, vestimenta limpa, itens de higiene pessoal, atendimento médico e jurídico, remédios, atividades físicas ou intelectuais, dentre outras precariedades.

As diretrizes que organizam o trabalho da Frente pelo Desencarceramento/RJ, estão relacionadas a: 1 ) Contribuir para a redução

\footnotetext{
11 Documentos emitidos pelo Mecanismo de Prevenção e Combate à Tortura do Rio de Janeiro (MEPCT/RJ) sobre os impactos da pandemia no sistema prisional. Disponível em: $<$ http://mecanismori.com.br/relatorios/> Acesso em: 08 set.2020.

${ }^{12} \mathrm{O} 2$ de janeiro de 2017, durante rebelião no Complexo Penitenciário Anísio Jobim (Manaus), 56 presos, foram mortos. No dia 6 de janeiro, outro massacre na Penitenciária Agrícola de Monte Cristo, na cidade de Boa Vista (Roraima), cobrou a vida de 31 presos. Em 15 de janeiro desse mesmo ano, em motim acontecido na penitenciária de Alcaçuz, em Natal (Rio Grande do Norte), mais 26 presos foram vítimas fatais da barbárie carcerária.

Para mais informações: BORGES, Rodolfo. Rebelião em presídio do Rio Grande do Norte deixa ao menos 26 mortos. Jornal "El país", 15 de janeiro de 2017. Disponível em: < https://brasil.elpais.com/brasil/2017/01/15/politica/1484515933 103479.html> Acesso em: 07 out. 2020.
} 
da superlotação, sem a criação de novas vagas. 2) Congregar e acoIher a participação de familiares de pessoas presas ou em medida de internação, bem como pessoas que tenham passado por medidas de restrição de liberdade. 3) Promover e divulgar pesquisas, aportando recomendações e dados para esferas de decisão de políticas públicas.4)Acompanhar as condições das unidades prisionais e socioeducativas, a partir dos relatos e documentos produzidos pelos órgãos de controle $^{13}$.

Além do mais, a Frente do Rio de Janeiro, contribui ativamente para a criação/consolidação de organizações similares em todos os estados da federação. O programa comum está sintetizado na chamada "Agenda Nacional pelo Desencarceramento".

Assim, essa organização nacional articula diversas instituições, coletivos e movimentos sociais, com o objetivo de construir um programa comum capaz de reduzir a população prisional do país. Alternativas como essas, entre outras, são essenciais para fortalecer as articulações e iniciativas com o objetivo de garantir o direito à vida das pessoas privadas de liberdade.

Na particularidade fluminense, a Frente Estadual, junto com o Mecanismo de Combate e Prevenção à $\operatorname{Tortura}^{14}$ (MCPT/RJ), exigem que, no âmbito dos Tribunais de Justiça do Estado, seja implementada a Recomendação no 62 do Conselho Nacional de Justiça $(\mathrm{CNJ})^{15}$, para efetivar o desencarceramento.

\footnotetext{
${ }^{13}$ Informação disponível em: <http://mecanismori.com.br/frente-estadual-pelo-desencarceramento-no-rio-de-janeiro-documento/> Acesso em: 28 set.2020.

${ }^{14} \mathrm{O}$ Mecanismo Estadual de Prevenção e Combate à Tortura do Rio de Janeiro (MEPCT/RJ) é um órgão criado pela Lei Estadual № 5.778 de 30 de junho de 2010, vinculado à Assembleia Legislativa do Estado do Rio de Janeiro. Apresenta como objetivo planejar, realizar e conduzir visitas periódicas e regulares a espaços de privação de liberdade, qualquer que seja a for ma ou fundamento de detenção, aprisionamento, contenção ou colocação em estabelecimento público ou privado de controle, vigilância, internação, abrigo ou tratamento, para verificar as condições em que se encontram submetidas as pessoas privadas de liberdade, com intuito de prevenir a tortura e outros tratamentos ou penas cruéis, desumanos e degradantes. Disponível em: <http://mecanismorj.com.br/wp-content/uploads/Relat\%C3\%B3rio-Parcial-do-MEPCTRJ-sobre-o-COVID19-no-sistema-prisional-atualizado-09.08.pdf > Acesso em: 30 set. 2020.

15 “Covid-19: CNJ emite recomendação sobre sistema penal e sistema socioeducativo". Disponível em: <https://www.cnj.jus.br/covid-19-cnj-emite-recomendacao-sobre-sistema-penal-esocioeducativo/> Acesso em: 20 set. 2020.
} 
O Conselho Nacional de Justiça (CNJ), através da recomendação supramencionada, emite orientação a tribunais e magistrados para adoção de medidas preventivas à propagação deste novo vírus no sistema prisional e socioeducativo. Neste sentido, a Frente e o Mecanismo, identificam a necessidade de não apenas os grupos de risco saírem do sistema, mas que exista redução de presos na porta de entrada, bem como a liberação de presos provisórios, que constituem, aproximadamente, $40 \%$ do total do contingente prisional.

Nessa direção, indica-se a reavaliação de prisões provisórias, especialmente quando se trate de mulheres em situação de maternidade, portadores de deficiência e indígenas; ou quando o estabelecimento estiver superlotado e sem atendimento médico.

Sugere-se, ainda, reavaliação das prisões preventivas com prazo superior a 90 dias ou que resultem de crimes menos graves, além de indicar que novas ordens de prisão devam respeitar "máxima excepcionalidade".

Recomenda-se, também, a opção de prisão domiciliar aos presos em regime aberto ou semiaberto ou quando houver sintomas da doença, assim como suspensão da obrigatoriedade de apresentação em juízo pelo prazo de 90 dias, nos casos aplicáveis.

A não execução da recomendação do CNJ é frequente nos tribunais do estado do Rio de Janeiro. Nesse sentido, e a título de ilustração, entre os dias 17 e 18 de abril de 2020, e em menos de 24 horas de diferença, morreram dois detentos no sistema penitenciário fluminense com suspeita de COVID-19, sendo um deles, uma pessoa de 73 anos $^{16}$. Por ser considerado grupo de risco, o Tribunal de Justiça do Rio de Janeiro (TJRJ) poderia ter concedido a prisão domiciliar para evitar esse contágio e, posteriormente, essa morte.

O preso de 73 anos, falecido no Rio de Janeiro, em 17 de abril, apresentava sintomas de COVID-19 desde o dia 9 de abril, e estava alocado em uma prisão superlotada, portanto, segundo a Recomendação CNJ 62/2020, poderia ter sido desencarcerado, todavia, não foi.

\footnotetext{
16“Primeira morte de preso pela Covid-19 no Brasil é registrada no Rio de Janeiro". Disponível em <https://ponte.org/primeira-morte-de-preso-pela-covid-19-no-brasil-e-registrada-nori/> Acesso em: 22 set. 2020.
} 
Ao constatar seu descumprimento, partidos e organizações políticas vinculados à defesa de direitos humanos, demandam a aprovação de um projeto de Lei (Lei n. 978 de 2020), de autoria do Deputado Federal Glauber Braga e da Deputada Federal Talíria Petrone (PSOL/RJ), que busca reduzir o número de pessoas presas como medida urgente para prevenir o contágio da COVID-19 no sistema prisional e socioeducativo.

Em nota oficial de apoio ${ }^{17}$, organismos de direitos humanos observam que o Projeto de Lei n. 978/2020 propõe medidas concretas de redução da população prisional e de adolescentes em cumprimento de medida socioeducativa de internação, em consonância à Resolução n. 62 do Conselho Nacional de Justiça ${ }^{18}$.

A substituição da pena privativa de liberdade em regime fechado ou semiaberto, das medidas socioeducativas de internação ou semiliberdade, ou mesmo da prisão provisória por prisão/internação domiciliar ou outras medidas cautelares alternativas à prisão para pessoas do grupo de risco, idosas, gestantes, lactantes e mães ou portadoras de doenças preexistentes, incluindo também, casos que não envolvam violência ou grave ameaça, com penas inferiores a 4 anos, é factível e evitará que pessoas sob a tutela do Estado estejam expostas a maior risco de contaminação e agravamento da doença, em razão das condições inconstitucionais a que são submetidas dentro do sistema prisional.

O PL 978/2020, está em plena conformidade com o que o ordenamento jurídico e com recomendações internacionais, como a divulgada, em abril de 2020, pela Corte Interamericana de Direitos Hu$\operatorname{manos}^{19}$.

\footnotetext{
${ }^{17}$ Assinam esta petição as seguintes organizações: MCPT/RJ, Centro de Estudos de Segurança e Cidadania - Cesec, Coletivo Arte Solidária, Autônoma e Militante - Coletivo ArtSam, Conectas Direitos Humanos, Gabinete de Assessoria Jurídica às Organizações Populares - GAJOP, Instituto Brasileiro de Ciências Criminais - IBCCRIM, Instituto de Defensores de Direitos Humanos - DDH, Instituto de Defesa do Direito de Defesa - IDDD, Instituto de Desenvolvimento de ações sociais - IDEAS, Instituto Sou da Paz, Instituto Terra, Trabalho e Cidadania - ITTC , Justiça Global, entre outras.

${ }^{18}$ Nota completa disponível em: <https://www.migalhas.com.br/quentes/324853/entidadesassinam-nota-de-apoio-a-pl-que-propoe-reducao-da-populacao-prisional> Acesso em: 22 set. 2020.

${ }^{19}$ Ver: "COVID-19 e Direitos Humanos: Os problemas e desafios devem ser abordados a partir de uma perspectiva de Direitos Humanos e com respeito às obrigações internacionais".
} 
Nesse sentido, a resolução elaborada por essa organização internacional, sugere que os estados membros se comprometam a: 1) Reduzir a superlotação; 2) Estabelecer protocolos ou planos de atuação para a prevenção do contágio de COVID-19; 3) Proporcionar às mulheres grávidas acesso gratuito a serviço de atenção à saúde sexual e reprodutiva assim como o serviço de atenção à maternidade e facilitar acesso a serviços de saúde adequados para meninas e meninos; 4) Prover alimentação suficiente e água potável; 5) Adotar medidas para assegurar a ventilação natural, limpeza máxima, desinfecção e coleta de resíduos para evitar que a doença se propague; 6)Distribuição gratuita de máscaras, luvas, álcool, toalhas descartáveis, papel higiênico e sacos de lixo, dentre outros elementos, tanto para a população que se encontra no estabelecimento, como para o pessoal de custódia e equipes de saúde; 7)Possibilitar o acesso a serviços de saúde mental para as pessoas que assim o requeiram, levando em conta a ansiedade e/ou outras patologias que possam ser geradas pelo temor advindo da situação do COVID-19.

Embora se reconheça a importância da normativa internacional, a formalidade do direito burguês, não se realiza no plano do real $^{20}$. O não cumprimento pelo Estado de todas essas recomendações; aliado às dificuldades de ingresso de familiares e organismos públicos de defesa de direitos humanos para monitoramento das violações de direitos, fez com que a Frente pelo Desencarceramento/RJ e o Mecanismo de Prevenção e Combate à Tortura/RJ, lançaram, em junho de 2020, a "Plataforma Desencarcera" ${ }^{21 " ; ~ f e r r a m e n t a ~ v i r t u a l ~ a ~}$ partir da qual podem ser realizadas denúncias anônimas durante a pandemia e facilitar a comunicação e os encaminhamentos pertinentes aos organismos públicos.

Disponível em: <http://corteidh.or.cr/docs/medidas/velez se 01.pdf> Acesso em: 30 set. 2020.

${ }^{20}$ Marx e Engels (1985) discutem o direito burguês como direito desigual, vale dizer, igualdade formal das leis e desigualdade real ou material. Se o Estado capitalista não é arbitro neutro acima e por fora dos interesses de classes, as leis tampouco são para todos/as iguais, não defendem os interesses de todos/as.

${ }^{21 “ M e c a n i s m o ~ d e ~ C o m b a t e ~ a ̀ ~ T o r t u r a ~ l a n c ̧ a ~ p l a t a f o r m a ~ o n-l i n e ~ p a r a ~ r e c e b i m e n t o ~ d e ~ d e n u ́ n-~}$ cias durante a pandemia". ALERJ, 8 de junho de 2020. Disponível em:

<http://www.alerj.ri.gov.br/Visualizar/Noticia/48866?AspxAutoDetectCookieSupport=1>

Acesso em: 13 set. 2020. 
Com isso, observa-se que órgãos de defesa de direitos humanos e de prevenção e combate à tortura vêm se articulando com outros organismos, inclusive internacionais, para diminuir os impactos da COVID-19 no sistema.

Deste modo, considera-se que, ignorar os efeitos dramáticos da entrada e proliferação da SARS-CoV-2, em um sistema prisional já superlotado, precário, insalubre e responsável por todo tipo de violações aos direitos humanos, faz parte de uma estratégia silenciosa do Estado brasileiro para continuar (e aprofundar), apolítica racista de eliminação de corpos de homens e mulheres, principalmente de jovens pobres e negros, considerados descartáveis, em um país marcado, até hoje, pela sua herança escravocrata.

\section{Seletividade punitiva e racismo}

Em 2017, segundo o Levantamento Nacional de Informações Penitenciárias (INFOPEN, 2017), o Brasil deixou de ser o quarto, para tornar-se o terceiro país do mundo com maior população penitenciária, com mais de 700 mil pessoas privadas de liberdade.

Segundo dados do Departamento de Informações Penitenciárias (DEPEN, 2017), 64\% da população prisional é negra. São principalmente jovens, com baixa escolaridade, desempregados/as e moradores/as das periferias das grandes cidades.

Do mesmo modo, em um dos países que mais mata mulheres no mundo, o superencarceramento no Brasil, revela-se também como um problema classista, racial e de gênero ${ }^{22}$.

Segundo o INFOPEN Mulheres (2018), no país, a população carcerária feminina passou de 5.601 para 42 mil entre 2000 e 2016. Esse dado é revelador porque demonstra que, em que pese o Brasil ocupar o quarto lugar em números absolutos com maior quantidade de mulheres presas no mundo, apenas atrás de Estados Unidos, China e Rússia; entre 2000 e 2016, as taxas de encarceramento desses países cresceram em proporções bem diferentes. Enquanto a taxa de 22 "A curva ascendente do encarceramento feminino". Revista Práxis no 103/Ano 2020/
CRESSRJ, p.16. Acesso em:16 set. 2020. 
Estados Unidos nesse período não chegou a $20 \%$, a de China subiu em $105 \%$ e a de Rússia diminui em $2 \%$, a de Brasil cresceu $455 \%$.

Com isso queremos dizer que, nos últimos anos e até hoje, Brasil é o primeiro país no ranking mundial pela velocidade com a que encarcera as mulheres de seu país. Mas, quem elas são?

Boiteux (2016, p.18), analisa o perfil das mulheres presas no Brasil e observa que $80 \%$ são mães, jovens (50\%), solteiras (57\%), negras (68\%), com baixa escolaridade (50\% com ensino fundamental incompleto), desempregadas ou inseridas em empregos precarizados, em prisão preventiva (32\%) ou condenadas principalmente a penas entre 4 e 8 anos (35\%), em regime fechado(45\%).

O delito de tráfico de drogas é o responsável por mais de $60 \%$ das detenções. A legislação antidrogas é o marco legal que possibilitou esse aumento exponencial da taxa de encarceramento feminino no Brasil.

Neste sentido, a atual lei de drogas (11.343/2006),abre brechas para interpretações subjetivistas e racistas que habilitam juízes a determinar sentenças como "usuárias" ou "traficantes", segundo a procedência social da acusada. Por ser considerado crime hediondo, as mulheres condenadas por tráfico praticamente não recebem indulto e as penas implicam, praticamente sempre, na privação da liberdade, apesar desses delitos, a maioria das vezes, serem cometidos sem violência.

Atualmente, a taxa de mulheres presas no país, é superior ao crescimento masculino, o que revela que a seletividade penal se alicerça na desigualdade de classe e gênero e na opressão étnico-racial.

Com relação ao debate entre sistema criminal e racismo, Angela Davis (2019) destaca que, - no discurso popular e acadêmico -, prevalece uma relação entre crime e castigo, considerada óbvia e natural. Ao problematizar essa vinculação, a autora, sustenta ser menos o delito, e sim a origem de classe e de raça, o que determina o processo de criminalização, ou seja, quem vai (ou não) à prisão.

O cárcere, na sua hipótese, é uma instituição profundamente conectada com a manutenção do racismo. O sistema carcerário torna natural a violência decretada contra as minorias raciais ao institucio- 
nalizar uma lógica circular viciosa: os negros estão presos porque são criminosos, e, se estão presos, é porque "mereceram".

Aliado ao racismo, as formulações liberais, retiram e ocultam do crime, as determinações políticas, econômicas e ideológicas que constituem e explicam esse fenômeno. Ao excluir a perspectiva de totalidade social, a culpa individualizada pelo crime cometido, legitima o Estado para a aplicação da pena de prisão.

Dessa forma, qualquer medida que autorizasse o desencarceramento em contexto da pandemia, colocaria "em risco à sociedade", reforçando o mito burguês da defesa social, cuja formulação se sustenta na ideia do Estado como defensor da sociedade do crime.

A população prisional vive sistematicamente seus direitos violados e práticas de tortura, como pena, permanecem. Neste sentido, seria possível falar em democracia racial ou negar racismo como pilar das desigualdades sociais no Brasil?(BORGES, 2018). Não há margem para dúvidas: são jovens negras e negros, o foco da ação genocida do Estado, no Brasil.

Essa seletividade punitiva (que é histórica) demarca com precisão quem é e continuará sendo as principais vítimas fatais da COVID-19 no sistema, caso não se adotem medidas eficazes como o desencarceramento, para conter a expansão da pandemia no interior dos presídios.

Mas, por que este governo de corte fascista se importaria com a vida e a saúde de presas e presos? Acaso o presidente do Banco Central do Brasil, Roberto Campos Neto, não disse aos investidores que reduzir mortes por coronavírus era pior para a economia ${ }^{23}$ ?

De acordo com Miranda (2020), assistimos a demora e os entreves burocráticos do governo para que trabalhadores/as que perderam seus empregos pela pandemia recebam o auxílio emergencial de 600 reais. Enquanto isso, o Ministro da Economia, Paulo Guedes,

\footnotetext{
${ }^{23}$ Audi, Amanda. "Presidente do BC diz a investidores que reduzir mortes por coronavírus é pior para a economia". Disponível em: <https://theintercept.com/2020/04/16/banco-central-presidente-coronavirus-economia/> Acesso em: 28 set. 2020.
} 
com celeridade, repassou $\mathrm{R} \$ 1,2$ trilhões ao mercado financeiro. ${ }^{24}$

A prioridade do governo é salvar os lucros e não a vida de trabalhadoras/es, ainda muito menos de presas/os, considerados por grande parte da sociedade, indesejáveis. Em contexto de pandemia, verifica-se a piora das já péssimas e inumanas condições de detenção, no sistema prisional brasileiro.

\section{Reflexões finais}

O modo de produção capitalista, pautado na busca incessante e crescente de lucro, determina uma disjunção radical entre produção para a satisfação das necessidades humanas e produção para a autorreprodução do capital. Existe uma completa subordinação das necessidades humanas à reprodução do valor, no interesse da autorrealização ampliada do capital. (MÉSZÁROS, 1996).

As causas da pandemia estão conectadas a este modo de produção, que se fundamenta na exploração e na superexploração da força de trabalho, no extermínio dos "sobrantes" e na apropriação predatória e consequente esgotamento dos recursos naturais, disponíveis no planeta.

De acordo com Miranda (2020), é preciso situar a pandemia como resultado do próprio capitalismo. É o capital que comanda a produção, que avança sobre a agricultura e a natureza seguindo sua busca ilimitada por lucros, que impõe padrões produtivos que acabam por produzir inúmeras doenças e determina uma distribuição espacial da população que favorece a propagação de doenças e vírus.

Diante da crise sanitária, a omissão e o descaso do governo federal para criar políticas necessárias à preservação da vida da classe trabalhadora, provocou (até outubro de 2020), mais de 150 mil mortos. Com relação às pessoas privadas de liberdade, em vez de promover o desencarceramento, a pandemia tem sido utilizada para suprimir direitos, mais uma vez.

\footnotetext{
${ }^{24}$ Miranda, Flávio. "Bancos e bilionários primeiro: a operação resgate do governo do capitão". Site EOL, abril de 2020. Disponível em: <https://esquerdaonline.com.br/2020/04/09/bancose-bilionarios-primeiro-operacao-resgate-do-governo-do-capitao/> Acesso em: 03 de out.2020.
} 
Ademais da falta de tratamento específico de saúde em casos de suspeitas ou confirmação de COVID-19 no sistema prisional e da proibição da entrada de familiares; o Estado suspendeu ou restringiu os atendimentos de advogados e defensores, que, na maioria das vezes, são os que recebem as denúncias de falta de água, comida estragada, violência e torturas.

Destarte, comprova-se neste estudo, que não houve redução drástica da superlotação, já que grupos de risco e pessoas presas por delitos sem violência ou baixo potencial ofensivo, mantiveram sua prisão decretada.

Diante deste cenário, considera-se fundamental para a categoria profissional de assistentes sociais, orientada por seu Projeto Ético-Político, investir em reflexões que possibilitem problematizar a pandemia buscando suas conexões (causas e desdobramentos) no movimento da totalidade social; destruindo as concepções fetichizadas que, por exemplo, atribuem a responsabilidade pelo contágio de seres humanos com a SARS-CoV-2, aos hábitos alimentares chine$\operatorname{ses}^{25}$.

Chama-se a atenção sobre a tarefa fundamental que continuaremos a ter: aliar as reflexões teóricas com propostas concretas de trabalho profissional que fortaleça mas articulações entre a categoria de assistentes sociais e as organizações sociais e políticas de defesa de direitos humanos.

Em acordo com Brites e Sales (2000), um projeto profissional que objetiva a realização e ampliação de direitos sociais e humanos só se mantém se contar com uma base social de sustentação política, o que coloca a práxis política como o meio adequado à realização da ética profissional.

Com isso, é essencial fortalecer atividades profissionais interdisciplinares, intersetoriais e coletivas que por um lado, contribuam para dar visibilidade pública à violação dos direitos humanos e pelo outro, sejam orientadas à construção de propostas alternativas ao cenário de barbárie capitalista que a pandemia intensificou.

${ }^{25}$ Ver: Korol, Claudia. No le hechen la culpa al murciélago. Jornal Página 12, abril de 2020. Disponível em: <https://www.pagina12.com.ar/256569-no-le-echen-la-culpa-al-murcielago> Acesso em: 2 set. 2020. 
Os limites e as possibilidades da ética profissional são dados pelas tendências estruturais e conjunturais da sociedade capitalista, como também pelo trabalho profissional orientado teleologicamente em função de um projeto coletivo (BARROCO, 2000).

Assim, objetivar relações mais livres é agir de forma que amplie a margem de autonomia de nossas ações, levando em conta a relação com os outros (BARRCO e TERRA, 2012). É participar de ações voltadas à liberação das formas de opressão que, no capitalismo, impedem a livre manifestação das capacidades e potencialidades humanas.

\section{Referências}

ASSEMBLEIA LEGISLATIVA do ESTADO do RIO DE JANEIRO. Mecanismo de Combate à Tortura lança plataforma on-line para recebimento de denúncias durante a pandemia". ALERJ, 8 de junho de 2020.Disponível em: <http://www.alerj.rj.gov.br/Visualizar/Noticia/48866?AspxAutoDetectCookieSupport=1>. Acesso em: 13 set. 2020.

AUDI, Amanda. Presidente do BC diz a investidores que reduzir mortes por coronavírus é pior para a economia". The Intercep Brasil, abril de 2020. Disponível em: <https://theintercept.com/ 2020/04/16/banco-central-presidente-coronavirus-economia/>. Acesso em: 28 set. 2020.

BARATTA, Alessandro. Criminología crítica y crítica del Derecho Penal. Buenos Aires: Siglo XXI, 2004.

BARROCO Maria Lucia. Os fundamentos sócio-históricos da ética. Modulo 04. CFESS-ABEPSS- CEAD/NED-UNb, 2000. . TERRA, Silvia. Código de Ética do/a Assistente Social comentado. São Paulo: Cortez, 2012.

BOITEUX, Luciana. Encarceramento feminino e seletividade penal. In: Rede de Justiça Criminal. Discriminação de gênero no sistema penal. Edição 9, Setembro de 2016.

BORGES, Juliana. O que é encarceramento em massa? Belo Horizonte - MG: Letramento: Justificando, 2018. 
BORGES, Rodolfo. Rebelião em presidio do Rio Grande do Norte deixa ao menos 26 mortos. Jornal El país, 15 de janeiro de 2017.Disponível em: <https://brasil.elpais.com/brasil/2017/01/15/politica/ 1484515933_103479.html>. Acesso em: 07 out. 2020.

BOSCHETTI, I. Expropriação de direitos e reprodução da força de trabalho. In: . (ORG). Expropriação e Direitos no capitalismo. São Paulo: Cortez, 2018.

BRITES, Cristina. SALES Mione Apolinário. Ética e práxis profissional. CFESS, Brasília, 2000.

CONSELHO NACIONA DE JUSTIÇA (CNJ). Covid-19: CNJ emite recomendação sobre sistema penal e sistema socioeducativo. Agência CNJ de Notícias, 17 março de 2020. Disponível em: <https:// www.cnj.jus.br/covid-19-cnj-emite-recomendacao-sobre-sistemapenal-e-socioeducativo/>. Acesso em: 20 set. 2020.

CONSELHO REGIONAL DE SERVIÇO SOCIAL (Rio de Janeiro). A curva ascendente do encarceramento feminino. Revista Práxis. CRESSRJVol. 16, no 103, 2020. Acesso em: 16 set. 2020.

CORTE INTERAMERICANA DE DIREITOS HUMANOS. COVID-19 e Direitos Humanos: Os problemas e desafios devem ser abordados a partir de uma perspectiva de Direitos Humanos e com respeito às obrigações internacionais. CIDH, abril de 2020. Disponível em: <http://corteidh.or.cr/docs/medidas/velez_se_01.pdf>. Acesso em: 30 set. 2020.

DAVIS, Angela. A democracia da abolição. Para além do Império, das prisões e da tortura. 2a Ed. - Rio de Janeiro: Difel, 2019.

DEPARTAMENTO PENITENCIÁRIO NACIONAL (DEPEN). Painéis de monitoramento de casos de Covid-19. Disponível em: <https://app.powerbi.com/view?r=eyJrljoiYThh-

Mjk5YjgtZWQwYS00ODIkLTg4NDgtZTFhMTgzYmQ2MGVIliwidCI6ImViMDkwNDIwLTQONGMINDNmNy05MWYyLTRiOGRhNmJmZThIMSJ9>. Acesso em: 01 out. 2020.

KOROL, Claudia. No le hechen la culpa al murciélago. Jornal Página 12, abril de 2020. Disponível em: <https://www.pagina12.com.ar/ 256569-no-le-echen-la-culpa-al-murcielago>. Acesso em: 2 set. 2020. 
Levantamento Nacional de Informações Penitenciárias: INFOPEN atualização - Junho de 2016. Brasília - DF: Ministério de Justiça e a Segurança Pública. Departamento Penitenciário Nacional, 2017.Disponível em: <http://depen.gov.br/DEPEN/noticias-1/noticias/infopenlevantamento-nacional-de-informacoes-penitenciarias-2016/relatorio_2016_22111.pdf>.

Levantamento Nacional de Informações Penitenciárias: INFOPEN Painel interativo - dezembro de 2019. Brasília - DF: Ministério de Justiça e a Segurança Pública. Departamento Penitenciário Nacional, 2019. Disponível em: <https://app.powerbi.com/view?r=eyJrljoiZTIkZGJjODQtNmJIMi00OTJhLWFIMDktNzRINmFkNTMOMWI3liwidCI6ImViMDkwNDIwLTQONGMtNDNmNy05MWYyLTRiOGRhNmJmZThIMSJ9>. Acesso em: 17 set. 2020.

Mecanismo Estadual de Prevenção e Combate à Tortura do Rio de Janeiro.Rio de Janeiro (Estado). "Boletim COVID-19 no sistema prisional". Organização: Mecanismo Estadual de Prevenção e Combate à Tortura do Rio de Janeiro. - Rio de Janeiro: MEPCT/RJ, 2020. Disponível em: <http://mecanismorj.com.br/relatorios/>. Acesso em: 05 out. 2020.

. Relatório parcial sobre os impactos do COVID-19 no sistema prisional do Rio de Janeiro. Organização: Mecanismo Estadual de Prevenção e Combate à Tortura do Rio de Janeiro. - Rio de Janeiro: MEPCT/RJ, agosto de 2020. Disponível em: <http://mecanismorj.com.br/wp-content/uploads/Relat\%C3\%B3rio-Parcial-do-MEPCTRJsobre-o-COVID19-no-sistema-prisional-atualizado-09.08.pdf>. Acesso em: 30 set. 2020.

. Nota técnica sobre Comunicação e Cartas durante a pandemia de COVID-19. Organização: Mecanismo Estadual de Prevenção e Combate à Tortura do Rio de Janeiro. - Rio de Janeiro: MEPCT/RJ, 2020. Disponível em: <http://mecanismorj.com.br/wp-content/uploads/Nota-T\%C3\%A9cnica-sobre-Comunica\%C3\%A7\%C3\%A3o-e-Cartas-durante-a-pandemia-de-COVID-MEPCTRJ.pdf>. Acesso em: 15 set. 2020. 
Levantamento Nacional de Informações Penitenciárias: INFOPEN MuIheres, 2ª Edição. Brasília - DF, 2018. Disponível em: <http://depen.gov.br/DEPEN/depen/sisdepen/infopen-mulheres/ infopenmulheres_arte_07-03-18.pdf>. Acesso em: 10set. 2020.

MELLO, Kátia. O sistema prisional brasileiro no contexto da pandemia de COVID-19. Portal Conexão UFRJ, 31 de março de 2020. Disponível em: <https://ufrj.br/noticia/2020/04/01/o-sistema-prisional-brasileiro-no-contexto-da-pandemia-de-covid-19>. Acesso em: 05 set. 2020.

MARX, Karl. ENGELS, Friedrich. Crítica do Programa de Gotha. Obras Escolhidas em Três Tomos. Tomo III. Moscovo: Progresso, 1985. MÉSZÁROS, István. Produção destrutiva e Estada Capitalista. São Paulo: Ed. Ensaio, 1996.

MIRANDA, Giuliana. Por coronavírus, Portugal aprova mecanismo que pode libertar até $15 \%$ da população carcerária. Jornal Folha de São Paulo, março de 2020. Disponível em: <https://www1.folha.uol.com.br/mundo/2020/04/para-reduzir-risco-de-covid-19-parlamentode-portugal-aprova-libertar-presos.shtml>. Acesso em: 15 de set. 2020.

MIRANDA, Flávio. Bancos e bilionários primeiro: a operação resgate do governo do capitão. Site EOL, abril de 2020. Disponível em: $<$ https://esquerdaonline.com.br/2020/04/09/bancos-e-bilionariosprimeiro-operacao-resgate-do-governo-do-capitao/>. Acesso em: 03 de out.2020.

. O desastre econômico e o COVID 19: a luta de classes pede passagem. Site EOL, março de 2020. Disponível em: <https://esquerdaonline.com.br/2020/03/25/o-desastre-economico-e-o-covid-19-aluta-de-classes-pede-passagem/>. Acesso em: 11 out. 2020.

SIMAS, Fábio. A tortura no superencarceramento brasileiro: Estado e criminalização na crise estrutural do capital. Tese (Doutorado em Serviço Social) - Rio de Janeiro: UERJ, Programa de Pós-Graduação em Serviço Social, 2020. 312p. 
STABILE, Arthur. Primeira morte de preso pela Covid-19 no Brasil é registrada no Rio de Janeiro. Site Ponte Org, 17 abril de 2020. Disponível em <https://ponte.org/primeira-morte-de-preso-pela-covid-19no-brasil-e-registrada-no-rj/>. Acesso em: 22 set. 2020.

\section{Sobre a autora}

Fernanda Kilduff - Professora do Departamento de Política Social e Serviço Aplicado da Escola de Serviço Social da Universidade Federal de Rio de Janeiro (DPS/ESS/UFRJ/Brasil). Pós Doutora (2017), Doutora (2015) e Mestre (2009) em Serviço Social (PPGSS/UFRJ). Licenciada em Trabalho Social (2003), Faculdade de Trabalho Social da Universidade Nacional de La Plata (FTS/UNLP/Argentina). Participa da Comissão de Direitos Humanos do Conselho Profissional de Serviço Social (CRESS-RJ/7ạ Região). Coordena o Projeto de Extensão “Mulheres Privadas de Liberdade e Universidade" (ESS/UFRJ). Integra o "Laboratório de Estudos e Pesquisas Marxistas em Política Social" (ESS/ PPGSS/UFRJ).

E-mail: f.kilduff@ess.ufri.br 